\title{
Challenges in Antifungal Therapy in Diabetes Mellitus
}

\author{
Sazlyna Mohd Sazlly Lim ${ }^{1,2}$, Mahipal Sinnollareddy ${ }^{3,4}$ and Fekade Bruck Sime ${ }^{1,4, *(D)}$ \\ 1 Centre for Translational Anti-Infective Pharmacodynamics, School of Pharmacy, University of Queensland, \\ Brisbane 4102, Australia; s.mohdsazllylim@uq.net.au \\ 2 Department of Medicine, Faculty of Medicine and Health Sciences, Universiti Putra Malaysia, \\ Seri Kembangan 43400, Malaysia \\ 3 Therapeutic Goods Administration, Canberra 2609, Australia; mahi716@gmail.com \\ 4 UQ Centre for Clinical Research, Faculty of Medicine, University of Queensland, Brisbane 4029, Australia \\ * Correspondence: f.sime@uq.edu.au; Tel.: +61-7-334-61910
}

Received: 31 August 2020; Accepted: 3 September 2020; Published: 6 September 2020

\begin{abstract}
Diabetic patients have an increased propensity to Candida sp. infections due to disease-related immunosuppression and various other physiological alterations. The incidence of candidiasis has increased in number over the years and is linked to significant morbidity and mortality in critically ill and immunosuppressed patients. Treatment of infection in diabetic patients may be complicated due to the various disease-related changes to the pharmacokinetics and pharmacodynamics (PK/PD) of a drug, including antifungal agents. Application of PK/PD principles may be a sensible option to optimise antifungal dosing regimens in this group of patients. Further studies on PK/PD of antifungals in patients with diabetes mellitus are needed as current data is limited or unavailable.
\end{abstract}

Keywords: Candida; biofilms; diabetes; candidiasis; pharmacokinetic; pharmacodynamic

\section{Introduction}

We read with great interest the review by Rodrigues et al. which described the epidemiology and pathophysiology of Candida sp. infection in patients with diabetes mellitus (DM) [1]. Diabetic patients are more susceptible to infections due to the hyperglycemic environment that promotes (1) immune dysfunction, such as damage to the neutrophil function, suppression of the antioxidant complex, and humoral immunity; (2) micro- and macro-angiopathies; (3) decrease in the germicidal activity of urine; (4) gastrointestinal and urinary motility dysfunction; (5) quantity of medical procedures in these patients [2].

Candida sp. such as C. albicans, C. glabrata, C. tropicalis, C. parapsilosis, and C. krusei cause opportunistic infections [3]. However, in individuals who are immunocompromised, such as patients with DM, these species can cause invasive infections. Numerous studies have shown the link between Candida sp. infection and DM [4-8]. One study reported a higher risk (4.4 times) of developing oral candidiasis in elderly patients with DM when compared with those without DM [4]. Several other studies described DM as one of the risk factors for vulvovaginal candidiasis in their cohorts [5,6]. Furthermore, a prospective case-control study reported DM in $62.5 \%$ of patients with Candida bloodstream infection [8].

High mortality rates have been reported for patients with Candida sp. infection, particularly in those with Candida sp. bloodstream infection. Barchiesi et al. [9] for example, reported a mortality rate of $28-45 \%$ in patients with candidaemia. Similarly, in an earlier study of candidaemia in immunocompromised patients, the mortality rates associated with C. krusei and C. albicans were $49 \%$ 
and $28 \%$, respectively [10]. Therefore, adequate treatment is of tremendous importance in this group of patients. However, treatment of infection in a diabetic patient is not as straight forward as those without DM, as we will discuss going forward.

\section{Effect of Diabetes Mellitus on the Pharmacokinetics of Antifungal}

It has been perceived that the pharmacokinetics (PK) and pharmacodynamics (PD) of drugs are altered in patients with DM [11]. DM may affect the pharmacokinetics of numerous drugs, including antifungals, by affecting absorption of the drug, either due to delayed gastric emptying or slower absorption. The prevalence of delayed gastric emptying in diabetic patients has ranged from $28 \%$ to $65 \%$ [12]. Several studies have demonstrated slower absorption of a drug such as tolazamide [13] and anti-tuberculosis drugs [14] in patients with DM.

DM can also change the distribution of drug via non-enzymatic glycation of albumin [15]. A study by Szkudlarek et al. [15] showed that non-enzymatic glycation of albumin causes structural change to albumin resulting in weaker interactions between ketoprofen and glycated albumin. Reduced drug-protein binding would, in turn, cause an increase in the unbound concentration of the drug, e.g., itraconazole, as shown in a study by Arredondo et al. [16], which looked at protein binding of itraconazole and fluconazole in patients with DM. Changes to the unbound concentration of antifungals are particularly important for antifungals that are highly protein-bound, such as amphotericin B (95-99\%) [17], itraconazole (99\%) [18], ketoconazole (84\%) [19], miconazole (93\%) [20], caspofungin (96\%) [21], anidulafungin (99\%) [18], and micafungin (99\%) [18]. Vanstraelen et al. [22] demonstrated a positive relationship between voriconazole plasma protein binding and plasma albumin concentrations in critically ill patients based on a multivariate analysis $(p<0.001)$. This observation indicated that higher unbound voriconazole concentrations is associated with decreasing albumin concentrations. Kurland et al. [23], on the other hand, found that hypoalbuminemia in critically ill patients was associated with higher caspofungin clearance $(r=-0.31 ; p=0.062)$.

DM could also impair drug distribution into tissues due to disease-induced microvascular changes and reduced vascular permeability. Given the incidence and severity of diabetic foot infections and possibility of reduced tissue distribution, antimicrobial tissues penetration in DM patients, particularly in the setting of diabetic foot infections is of interest. The difference in tissue penetration in DM patients appear to be dependent on local blood flow, capillary density, and to some extent on the acute inflamed foot lesions $[24,25]$. In patients with chronic diabetes and chronic foot infections, drug tissue penetration is bound to be lower than other patients. Although data on antifungal drugs is lacking, studies have demonstrated that antibiotics like vancomycin, fosfomycin, and macrolides (except for telithromycin), which in general distributes well into tissues, appear to have significantly reduced tissue distribution in DM patients. Whereas for antibiotics like oxazolidinones, daptomycin, tigecycline, and fluoroquinolones, the tissue distribution tends to be sufficient and independent of disease state $[24,25]$.

DM is also associated with liver diseases such as non-alcoholic fatty liver disease [26] and diabetic hepatosclerosis [27], causing abnormal hepatic function, which may affect drug biotransformation. The impact of diabetes on drug biotransformation has been observed in animal models [28,29]. Watkins et al. [28] demonstrated in their study that biliary excretion of acetaminophen decreased by $65 \%$, with a $280 \%$ increase in urinary excretion, resulting in unaltered total clearance. Antifungals such as itraconazole, voriconazole, and micafungin undergo hepatic metabolism, which would be affected in the setting of hepatic impairment [18]. Changes to the hepatic metabolism of a drug will also affect its serum concentration. Micafungin, for example, exhibited reduced exposure in patients with moderate hepatic impairment (Child-Pugh score 7-9) in comparison with healthy volunteers (mean $\mathrm{AUC}_{0-\infty}, 97.5$ versus $125.9 \mu \mathrm{g} . \mathrm{h} / \mathrm{mL}, p=0.03$ ) [30]. 


\section{Challenges in the Treatment of Candida sp. Infections in Diabetic Patients}

\subsection{Antifungal Resistance}

Rodrigues et al. [1] mentioned in their review how hyperglycaemia in diabetic mice reduced the susceptibility of Candida sp. to voriconazole and amphotericin B [31]. Reduced susceptibility to antifungals in diabetic patients has also been demonstrated in the clinical setting [32-34]. Bhuyan et al. [32] observed a significant difference in the number of $C$. albicans and C. parapsilosis that is resistant to fluconazole in diabetes patients compared to healthy controls. Similarly, a higher proportion of patients with DM (47\%) were reported to have Candida sp. isolates that are resistant against ketoconazole in another study [33]. Furthermore, Al-Attas et al. [34] found that the Candida sp. isolated from their diabetic patients had higher rates of resistance to five antifungal drugs (flucytosine, fluconazole, ketoconazole, miconazole, econazole). In contrast, in the healthy controls, none of the isolated yeast showed any resistance to the tested antifungal agents.

Antifungal resistance is associated with poorer clinical outcomes [35]. Studies have shown better clinical outcomes in patients with candidemia, and mucosal candidiasis due to C. albicans, C. tropicalis, and C. parapsilosis isolates that are susceptible to fluconazole, as compared to those with fluconazole-resistant isolates (92\% success rate for 550 events for which the fluconazole minimum inhibitory concentration (MIC) is $\leq 2 \mathrm{mg} / \mathrm{L}, 83 \%$ success among 52 events for which the MIC is $4 \mathrm{mg} / \mathrm{mL}$, and 37\% success among 212 events for which the MIC is $8 \mathrm{mg} / \mathrm{L}$ ) [35]. Furthermore, Baddley et al. [36] reported lower mortality in patients with candidemia caused by fluconazole-susceptible isolates as compared with those due to fluconazole-resistant strains ( $25.4 \%$ vs. $60 \%)$.

\subsection{Biofilm Formation}

As highlighted by Rodrigues et al. [1], biofilm formation by Candida sp. is a significant factor that hampers effective treatment of fungal infections. Most of the infections caused by Candida sp. are the result of biofilm formation. Candida sp. can form biofilm on various surfaces, including Hickman catheters, soft contact lenses, urethral stents, and corneas [37]. Biofilms provide the Candida sp. refuge to tolerate high concentrations of antifungals [38]. Biofilm infections are, therefore, resistant to antifungal agents and more problematic to treat than infections with planktonic cells [39]. In a case-control study to ascertain the predictors of persistent candidemia and investigate the effect of biofilm formation by Candida sp. isolates in adult patients with candidemia, Li et al. [40] found that biofilm formation by C. albicans, C. tropicalis, and C. glabrata strains was significantly higher in patients with persistent candidemia than in the controls. They also demonstrated that infection with higher biofilm-forming strains of Candida sp. is associated with persistent candidemia (Adjusted odds ratio, 8.03; 95\% confidence interval, $2.50-25.81 ; p<0.01)$.

Chandra et al. [41] reported that C. albicans biofilms formed on denture acrylics in vitro displayed resistance to amphotericin B, nystatin, and fluconazole. On the contrary, the same isolate grown planktonically were susceptible to these agents. El-Azizi et al. [42] assessed the effect of amphotericin $B$ and voriconazole against the biofilm and the biofilm-dispersed cells of $C$. albicans using an in vitro biofilm model. The MIC of voriconazole and amphotericin B against the tested isolate was 0.0325 and $0.25 \mathrm{mg} / \mathrm{L}$, respectively. Five doses of amphotericin B or voriconazole were delivered to 2-, 5-, and 10-day-old biofilms at initial concentrations of 2 and $3 \mathrm{~m} / \mathrm{L}$, respectively. The study showed that voriconazole or amphotericin B were unable to eradicate C. albicans biofilm, stop cell dispersion from the biofilm or cease the progression of resistance to the antifungal agents.

Paradoxical effect of echinocandins, such as caspofungin, on Candida sp. biofilms have also been documented $[43,44]$. Paradoxical growth is defined as regrowth in the presence of drug concentrations above the MIC [43]. It has been demonstrated in in vitro studies that paradoxical growth occurred more frequently in C. albicans, C. parapsilosis, C. orthopsilosis, and C. metapsilosis isolates or C. tropicalis when they were grown as biofilms than when they were grown planktonically $[43,44]$. 


\section{Application of PK/PD Concepts in Optimisation of Antifungal Dosing}

Unfortunately, studies exploring the PK and PD of antifungals for the treatment of Candida sp. infections in patients with DM are limited. However, the potential for PK changes of antimicrobials is clear. The physiological changes that drive PK/PD alteration in other patient populations e.g., critically ill patients in intensive care units and hemato-oncological patients with neutropenia are also present in patients with DM as highlighted above. In that context, to illustrate the potential of PK/PD application in the optimisation of antifungal dosing regimens, studies involving critically ill patient populations are discussed here.

Considering the obstacles of providing effective treatment for Candida sp. infection in diabetic patients as mentioned above, applying PK/PD concepts to make optimum antifungal dosing should be deemed fundamental. PK/PD optimised antifungal dosing regimens are likely needed to ensure a successful treatment outcome while minimising side effects and the emergence of resistance. Table 1 summarises several PK/PD studies evaluating the dosing regimens of antifungals used for Candida sp. infections in critically ill patients.

Mouton et al. [45] described the area under the concentration-time curve for the unbound drug fraction/MIC ratio ( $f$ AUC/MIC) as the PK/PD index that is associated with the efficacy of fluconazole. Based on their in-silico study of fluconazole, the authors demonstrated that infections caused by Candida sp. with MICs up to $2 \mathrm{mg} / \mathrm{L}$ have a high probability of cure if an $f$ AUC/MIC target value of 100 is applied. They also concluded that the treatment of infections caused by Candida sp. can be optimised, according to the MIC of the strains.

In a population pharmacokinetic study of fluconazole in critically ill nonobese, obese, and morbidly obese patients by Alobaid et al. [46], the authors revealed that a fluconazole dose of $200 \mathrm{mg}$ daily administered intravenously was insufficient to achieve an $f$ AUC/MIC of 100 for strains with MICs of $\geq 2 \mathrm{mg} / \mathrm{L}$ in patients with BMI of $>30 \mathrm{~kg} / \mathrm{m}^{2}$. Therefore, a weight-based dosing regimen is more prudent in achieving the PK/PD index target. They found that an intravenous fluconazole loading dose of $12 \mathrm{mg} / \mathrm{kg}$ and maintenance dose of $6 \mathrm{mg} / \mathrm{kg} /$ day achieved PK/PD target for strains with higher MICs.

In an observational study by Ghanem-Zoubi et al. [47] which looked at the association between the AUC/MIC of fluconazole and clinical outcomes in patients with candidemia, the authors discovered that higher doses of fluconazole are needed to treat Candida sp. with high MICs. For C. glabrata, a higher AUC/MIC was observed among 30-day survivors with a median (interquartile range) of 230 $(77,539)$ compared to $96(75,164)$ in non-survivors. $(p=0.008)$, in parallel with a trend for lower MIC values, median $7(1,2)$ vs. $16(8,24) \mathrm{mg} / \mathrm{L}(p=0.06)$, respectively.

Treatment of fungal infection in patients on renal replacement therapy has also been challenging. Pérez-Pitarch et al. [48] showed in their study that the approved regimen of caspofungin is inadequate to obtain the PK/PD targets (targeted AUC/MIC ratios were 865 for C. albicans, 450 for C. glabrata and 1185 for C. parapsilosis) in critically ill patients on hemodiafiltration. The approved regimen (loading dose of $70 \mathrm{mg}$ and a daily maintenance dose of $50 \mathrm{mg}$ in patients with body weight $\leq 80 \mathrm{~kg}$ or $70 \mathrm{mg}$ when body weight is higher than $80 \mathrm{~kg}$ ) was only able to achieve $16.8 \%$ and $54.1 \%$ probability of target attainment against the PK/PD target for $C$. parapsilosis, and C. albicans isolates, respectively, with MIC $\geq$ $0.1 \mathrm{mg} / \mathrm{L}$, as demonstrated by their in silico analysis. 
Table 1. PK/PD studies evaluating the dosing regimens of antifungals used for Candida sp. infections.

\begin{tabular}{|c|c|c|c|c|c|c|}
\hline Reference & Antifungal Tested & Study Design & Patient Population & Dosing Regimens Tested/Simulated & PK/PD Target & Finding \\
\hline \multirow[t]{2}{*}{ Martial (2017) [49] } & \multirow[t]{2}{*}{ Micafungin } & \multirow[t]{2}{*}{ PK study, in silico } & \multirow[t]{2}{*}{ ICU, critically ill } & \multirow{2}{*}{$\begin{array}{l}\text { (I) } 100 \mathrm{mg} \text { QD for } 14 \text { days and (II) } 100 \mathrm{mg} \text { QD the first } 4 \text { days with } \\
200 \mathrm{mg} \text { QD from day } 5 \text { (labelled indication for non-responders); } \\
\text { alternative regimens included (III) } 200 \mathrm{mg} \text { loading dose on day } 1 \\
\text { followed by } 100 \mathrm{mg} \text { QD from day 2, (IV) } 200 \mathrm{mg} \text { loading dose } \\
\text { followed by } 150 \mathrm{mg} \text { QD from day } 2 \text { and (V) } 200 \mathrm{mg} \text { QD. }\end{array}$} & AUC/MIC >3000 & $\begin{array}{l}\text { PTA was }>91 \% \text { on day } 14 \text { for } \\
\text { MIC } 0.016 \mathrm{mg} / \mathrm{L} \text { for all of the } \\
\text { dosing regimens but decreased } \\
\text { to (I) } 44 \% \text {, (II) } 91 \% \text {, (III) } 44 \% \text {, } \\
\text { (IV) } 78 \% \text { and (V) } 91 \% \text { for MIC } \\
0.032 \mathrm{mg} / \mathrm{L} \text {. }\end{array}$ \\
\hline & & & & & AUC/MIC > 5000 & $\begin{array}{l}\text { PTA varied between } 62 \text { and } \\
96 \% \text { on day } 14 \text { for MIC } 0.016 \\
\text { mg/L. }\end{array}$ \\
\hline Jullien (2017) [50] & Micafungin & PK study, in silico & ICU, critically ill & $100,150,200,250$ and $300 \mathrm{mg}$ QD & AUC/MIC > 5000 & $\begin{array}{c}\text { For MICs } \geq 0.015-0.016 \mathrm{mg} / \mathrm{L}, \\
\text { high PTA necessitated doses } \\
\text { between } 150 \text { and } 300 \mathrm{mg} .\end{array}$ \\
\hline Grau (2015) [51] & Micafungin & PK study, in silico & ICU, critically ill & 100, 150 and $200 \mathrm{mg}$ QD & $\begin{array}{c}\mathrm{AUC} / \mathrm{MIC}>285 \text { or } \\
>3000\end{array}$ & $\begin{array}{l}\geq 90 \% \text { PTA can be achieved for } \\
\text { Candida spp. and C. parapsilosis } \\
\text { MICs of } 0.008-0.016 \text { and } \\
0.125-0.25 \mathrm{mg} / \mathrm{L} \text {, respectively } \\
\text { for all dosing regimens. }\end{array}$ \\
\hline $\begin{array}{l}\text { Pérez Civantos } \\
\text { (2019) [52] }\end{array}$ & Anidulafungin & PK study & $\begin{array}{l}\text { ICU, critically ill, } \\
\text { peritonitis }\end{array}$ & $200 \mathrm{mg}$ on day 1 , then $100 \mathrm{mg}$ QD & - & $\begin{array}{c}\text { Anidulafungin at conventional } \\
\text { doses reaches peritoneal fluid } \\
\text { concentrations that exceed the } \\
\text { minimum inhibitory } \\
\text { concentration of the usual } \\
\text { Candida spp. }\end{array}$ \\
\hline $\begin{array}{l}\text { García-de-Lorenzo } \\
\text { (2016) [53] }\end{array}$ & Micafungin & PK study, in silico & $\begin{array}{l}\text { ICU, critically ill, } \\
\text { burns }\end{array}$ & 100, 150 and $200 \mathrm{mg}$ QD & $\begin{array}{c}\mathrm{AUC} / \mathrm{MIC}>285 \text { or } \\
>3000\end{array}$ & $\begin{array}{l}\text { Micafungin at } 100 \mathrm{mg} / \text { day } \\
\text { achieved the PTA for MIC } \\
\text { values of } \leq 0.008 \mathrm{mg} / \mathrm{L} \text { and } \\
\leq 0.064 \mathrm{mg} / \mathrm{L} \text { for non-parapsilosis } \\
\text { Candida spp. and C. parapsilosis } \\
\text { isolates, respectively }\end{array}$ \\
\hline $\begin{array}{l}\text { Sinnollareddy } \\
\text { (2015) [54] }\end{array}$ & Fluconazole & PK study, in silico & ICU, critically ill & $400 \mathrm{mg}$ QD & AUC/MIC >100 & $\begin{array}{l}\text { PTA was } 92 \% \text { and } 67 \% \text { in } \\
\text { plasma and } \\
\text { subcutaneous-tissue interstitial } \\
\text { fluid, respectively, for C. albican } \\
\text { isolates with MIC of } 1 \mathrm{mg} / \mathrm{L} \text {. } \\
\text { Higher doses is required in } \\
\text { order to achieve the PK/PD } \\
\text { target in the } \\
\text { subcutaneous-tissue interstitial } \\
\text { fluid. }\end{array}$ \\
\hline Bergner (2006) [55] & Fluconazole & PK study & $\begin{array}{l}\text { ICU, critically ill, } \\
\text { CVVHF }\end{array}$ & $800 \mathrm{mg}$ QD & - & $\begin{array}{l}\text { A dosage of } 800 \mathrm{mg} / \text { day is } \\
\text { required in patients receiving } \\
\text { CVVHF to achieve Cmax of } 16 \\
\text { to } 32 \mathrm{mg} / \mathrm{L} .\end{array}$ \\
\hline
\end{tabular}

PK, pharmacokinetics; PD, pharmacodynamics; ICU, intensive care unit; $\mathrm{QD}$, once daily; CVVHF, continuous venovenous hemofiltration; AUC/MIC, area under the concentration-time curve/minimum inhibitory concentration ratio; MIC, minimum inhibitory concentration; PTA, probability of target attainment. 


\section{Conclusions}

Taken altogether, existing evidence suggests that disease-driven changes in the PK/PD of antifungals can occur in DM patients affecting the ability of conventional dosing regimens to ensure effective therapy. It is, therefore, important to apply PK/PD guided dose optimisation strategies for maximising patient outcomes. However, primary data available directly from DM patients is limited to enable robust PK/PD analysis and the design optimal regimens. Therefore, further studies on antifungal $\mathrm{PK} / \mathrm{PD}$ in $\mathrm{DM}$ patients with fungal infections are urgently need.

Author Contributions: Conceptualisation, S.M.S.L. and F.B.S.; Writing-original draft preparation, S.M.S.L.; Writing-review and editing, S.M.S.L., M.S., and F.B.S.; Supervision, F.B.S. All authors have read and agreed to the published version of the manuscript.

Funding: This research received no external funding.

Conflicts of Interest: The authors declare no conflict of interest.

\section{References}

1. Rodrigues, C.F.; Rodrigues, M.E.; Henriques, M. Candida sp. Infections in patients with diabetes mellitus. J. Clin. Med. 2019, 8, 76. [CrossRef] [PubMed]

2. Casqueiro, J.; Casqueiro, J.; Alves, C. Infections in patients with diabetes mellitus: A review of pathogenesis. Ind. J. Endocrinol. Metab. 2012, 16 (Suppl. S1), S27-S36. [CrossRef]

3. Spampinato, C.; Leonardi, D. Candida infections, causes, targets, and resistance mechanisms: Traditional and alternative antifungal agents. BioMed. Res. Int. 2013, 2013, 204237. [CrossRef] [PubMed]

4. Bianchi, C.M.; Bianchi, H.A.; Tadano, T.; Paula, C.R.; Hoffmann-Santos, H.D.; Leite, D.P., Jr.; Hahn, R.C. Factors related to oral candidiasis in elderly users and non-users of removable dental prostheses. Rev. Inst. Med. Trop. Sao Paulo 2016, 58, 17. [CrossRef]

5. Arfiputri, D.S.; Hidayati, A.N.; Handayani, S.; Ervianti, E. Risk factors of vulvovaginal candidiasis in dermato-venereology outpatients clinic of soetomo general hospital, surabaya, indonesia. Afr. J. Infect. Dis. 2018, 12, 90-94. [CrossRef]

6. Akimoto-Gunther, L.; Bonfim-Mendonça, P.d.S.; Takahachi, G.; Irie, M.M.T.; Miyamoto, S.; Consolaro, M.E.L.; Svidzinsk, T.I.E. Highlights regarding host predisposing factors to recurrent vulvovaginal candidiasis: Chronic stress and reduced antioxidant capacity. PLOS ONE 2016, 11. [CrossRef]

7. Sampath, A.; Weerasekera, M.; Dilhari, A.; Gunasekara, C.; Bulugahapitiya, U.; Fernando, N.; Samaranayake, L. Type 2 diabetes mellitus and oral candida colonization: Analysis of risk factors in a sri lankan cohort. Acta Odontol. Scand. 2019, 77, 508-516. [CrossRef]

8. Stojanovic, P.; Stojanovic, N.; Stojanovic-Radic, Z.; Arsić Arsenijević, V.; Otasevic, S.; Randjelovic, P.; Radulović, N.S. Surveillance and characterization of candida bloodstream infections in a serbian tertiary care hospital. J. Infect. Dev. Ctries 2016, 10, 643-656. [CrossRef]

9. Barchiesi, F.; Orsetti, E.; Mazzanti, S.; Trave, F.; Salvi, A.; Nitti, C.; Manso, E. Candidemia in the elderly: What does it change? PLoS ONE 2017, 12. [CrossRef]

10. Abbas, J.; Bodey, G.P.; Hanna, H.A.; Mardani, M.; Girgawy, E.; Abi-Said, D.; Whimbey, E.; Hachem, R.; Raad, I. Candida krusei fungemia: An escalating serious infection in immunocompromised patients. Arch. Intern. Med. 2000, 160, 2659-2664. [CrossRef]

11. Dostalek, M.; Akhlaghi, F.; Puzanovova, M. Effect of diabetes mellitus on pharmacokinetic and pharmacodynamic properties of drugs. Clin. Pharmacokinet. 2012, 51, 481-499. [CrossRef] [PubMed]

12. Horowitz, M.; Wishart, J.; Jones, K.; Hebbard, G. Gastric emptying in diabetes: An overview. Diabet. Med. A J. Br. Diabet. Assoc. 1996, 13, S16-S22.

13. Della-Coletta, A.; Eller, M. The bioavailability of tolazamide in diabetic patients and healthy subjects. Pharmacol. Res. 1988, 5, 174.

14. Kumar, A.K.; Chandrasekaran, V.; Kannan, T.; Murali, A.L.; Lavanya, J.; Sudha, V.; Swaminathan, S.; Ramachandran, G. Anti-tuberculosis drug concentrations in tuberculosis patients with and without diabetes mellitus. Eur. J. Clin. Pharmacol. 2017, 73, 65-70. [CrossRef] 
15. Szkudlarek, A.; Sułkowska, A.; Maciążek-Jurczyk, M.; Chudzik, M.; Równicka-Zubik, J. Effects of non-enzymatic glycation in human serum albumin. Spectroscopic analysis. Spectrochim. Acta A Mol. Biomol. Spectrosc. 2016, 152, 645-653. [CrossRef]

16. Arredondo, G.; Suárez, E.; Calvo, R.; Vazquez, J.A.; García-Sanchez, J.; Martinez-Jordá, R. Serum protein binding of itraconazole and fluconazole in patients with diabetes mellitus. J. Antimicrob. Chemother. 1999, 43, 305-307. [CrossRef]

17. Bekersky, I.; Fielding, R.M.; Dressler, D.E.; Lee, J.W.; Buell, D.N.; Walsh, T.J. Plasma protein binding of amphotericin $\mathrm{b}$ and pharmacokinetics of bound versus unbound amphotericin $\mathrm{b}$ after administration of intravenous liposomal amphotericin $\mathrm{b}$ (ambisome) and amphotericin $\mathrm{b}$ deoxycholate. Antimicrob. Agents Chemother. 2002, 46, 834-840. [CrossRef]

18. Bellmann, R.; Smuszkiewicz, P. Pharmacokinetics of antifungal drugs: Practical implications for optimized treatment of patients. Infection 2017, 45, 737-779. [CrossRef]

19. Levine, H.B. Ketoconazole in the Management of Fungal Disease; ADIS Press: Balgowlah, Australia, 1982.

20. Stevens, D.A. Miconazole in the Treatment of Systemic Fungal Infections; American Lung Association: Chicago, IL, USA, 1977.

21. Stone, J.A.; Xu, X.; Winchell, G.A.; Deutsch, P.J.; Pearson, P.G.; Migoya, E.M.; Mistry, G.C.; Xi, L.; Miller, A.; Sandhu, P.; et al. Disposition of caspofungin: Role of distribution in determining pharmacokinetics in plasma. Antimicrob. Agents Chemother. 2004, 48, 815-823. [CrossRef]

22. Vanstraelen, K.; Wauters, J.; Vercammen, I.; de Loor, H.; Maertens, J.; Lagrou, K.; Annaert, P.; Spriet, I. Impact of hypoalbuminemia on voriconazole pharmacokinetics in critically ill adult patients. Antimicrob. Agents Chemother. 2014, 58, 6782-6789. [CrossRef]

23. Kurland, S.; Furebring, M.; Löwdin, E.; Eliasson, E.; Nielsen, E.I.; Sjölin, J. Pharmacokinetics of caspofungin in critically ill patients in relation to liver dysfunction: Differential impact of plasma albumin and bilirubin levels. Antimicrob. Agents Chemother. 2019, 63. [CrossRef] [PubMed]

24. Muller, M.; dela Pena, A.; Derendorf, H. Issues in pharmacokinetics and pharmacodynamics of anti-infective agents: Distribution in tissue. Antimicrob. Agents Chemother. 2004, 48, 1441. [CrossRef] [PubMed]

25. Ray, A.; Malin, D.; Nicolau, D.P.; Wiskirchen, D.E. Antibiotic tissue penetration in diabetic foot infections a review of the microdialysis literature and needs for future research. J. Am. Podiatr. Med. Assoc. 2015, 105, 520-531. [CrossRef] [PubMed]

26. Chan, W.K.; Tan, A.T.B.; Vethakkan, S.R.; Tah, P.C.; Vijayananthan, A.; Goh, K.L. Non-alcoholic fatty liver disease in diabetics-prevalence and predictive factors in a multiracial hospital clinic population in $\mathrm{m}$ alaysia. J. Gastroenterol. Hepatol. 2013, 28, 1375-1383. [CrossRef] [PubMed]

27. King, R.; Harrison, L.; Gilbey, S.; Santhakumar, A.; Wyatt, J.; Jones, R.; Bodansky, H. Diabetic hepatosclerosis: Another diabetes microvascular complication? Diabet. Med. 2016, 33, e5-e7. [CrossRef]

28. Watkins, J.B.; Sherman, S.E. Long-term diabetes alters the hepatobiliary clearance of acetaminophen, bilirubin and digoxin. J. Pharmacol. Exp. Ther. 1992, 260, 1337.

29. Shankar, K.; Vaidya, V.S.; Apte, U.M.; Manautou, J.E.; Ronis, M.J.J.; Bucci, T.J.; Mehendale, H.M. Type 1 diabetic mice are protected from acetaminophen hepatotoxicity. Toxicol. Sci. 2003, 73, 220-234. [CrossRef]

30. Hebert, M.F.; Smith, H.E.; Marbury, T.C.; Swan, S.K.; Smith, W.B.; Townsend, R.W.; Buell, D.; Keirns, J.; Bekersky, I. Pharmacokinetics of micafungin in healthy volunteers, volunteers with moderate liver disease, and volunteers with renal dysfunction. J. Clin. Pharmacol. 2005, 45, 1145-1152. [CrossRef]

31. Mandal, S.M.; Mahata, D.; Migliolo, L.; Parekh, A.; Addy, P.S.; Mandal, M.; Basak, A. Glucose directly promotes antifungal resistance in the fungal pathogen, Candida spp. J. Biol. Chem. 2014, 289, 25468-25473. [CrossRef]

32. Bhuyan, L.; Hassan, S.; Dash, K.C.; Panda, A.; Behura, S.S.; Ramachandra, S. Candida species diversity in oral cavity of type 2 diabetic patients and their in vitro antifungal susceptibility. Contemp. Clin. Dent. 2018, 9, S83. [CrossRef]

33. Bremenkamp, R.; Caris, A.; Jorge, A.; Back-Brito, G.N.; Mota, A.; Balducci, I.; Brighenti, F.L.; Koga-Ito, C. Prevalence and antifungal resistance profile of candida spp. Oral isolates from patients with type 1 and 2 diabetes mellitus. Arch. Oral Biol. 2011, 56, 549-555. [CrossRef] [PubMed]

34. Al-Attas, S.A.; Amro, S.O. Candidal colonization, strain diversity, and antifungal susceptibility among adult diabetic patients. Ann. Saudi Med. 2010, 30, 101-108. [CrossRef] [PubMed] 
35. Pfaller, M.A. Antifungal drug resistance: Mechanisms, epidemiology, and consequences for treatment. Am. J. Med. 2012, 125, S3-S13. [CrossRef]

36. Baddley, J.W.; Patel, M.; Bhavnani, S.M.; Moser, S.A.; Andes, D.R. Association of fluconazole pharmacodynamics with mortality in patients with candidemia. Antimicrob. Agents Chemother. 2008, 52, 3022-3028. [CrossRef] [PubMed]

37. Chandra, J.; Mukherjee, P.K. Candida biofilms: Development, architecture, and resistance. Microbiol. Spectr. 2015, 3. [CrossRef]

38. Gao, J.; Wang, H.; Li, Z.; Wong, A.H.-H.; Wang, Y.-Z.; Guo, Y.; Lin, X.; Zeng, G.; Liu, H.; Wang, Y. Candida albicans gains azole resistance by altering sphingolipid composition. Nat. Commun. 2018, 9, 1-14. [CrossRef]

39. Silva, S.; Rodrigues, C.F.; Araújo, D.; Rodrigues, M.E.; Henriques, M. Candida species biofilms' antifungal resistance. J. Fungi 2017, 3. [CrossRef]

40. Li, W.S.; Chen, Y.C.; Kuo, S.F.; Chen, F.J.; Lee, C.H. The impact of biofilm formation on the persistence of candidemia. Front. Microbiol. 2018, 9, 1196. [CrossRef]

41. Chandra, J.; Mukherjee, P.K.; Leidich, S.D.; Faddoul, F.F.; Hoyer, L.L.; Douglas, L.J.; Ghannoum, M.A. Antifungal resistance of candidal biofilms formed on denture acrylic in vitro. J. Dent. Res. 2001, 80, 903-908. [CrossRef]

42. El-Azizi, M.; Farag, N.; Khardori, N. Antifungal activity of amphotericin b and voriconazole against the biofilms and biofilm-dispersed cells of candida albicans employing a newly developed in vitro pharmacokinetic model. Ann. Clin. Microbiol. Antimicrob. 2015, 14, 21. [CrossRef]

43. Melo, A.S.; Colombo, A.L.; Arthington-Skaggs, B.A. Paradoxical growth effect of caspofungin observed on biofilms and planktonic cells of five different candida species. Antimicrob. Agents Chemother. 2007, 51, 3081-3088. [CrossRef] [PubMed]

44. Ferreira, J.A.G.; Carr, J.H.; Starling, C.E.F.; de Resende, M.A.; Donlan, R.M. Biofilm formation and effect of caspofungin on biofilm structure of candida species bloodstream isolates. Antimicrob. Agents Chemother. 2009, 53, 4377-4384. [CrossRef] [PubMed]

45. Charles, H.N.; Ambrose, P.G.; Drusano, G.L.; Murakawa, T. Antimicrobial Pharmacodynamics in Theory and Clinical Practice; CRC Press: Boca Raton, FL, USA, 2007; pp. 339-366.

46. Alobaid, A.S.; Wallis, S.C.; Jarrett, P.; Starr, T.; Stuart, J.; Lassig-Smith, M.; Mejia, J.L.; Roberts, M.S.; Sinnollareddy, M.G.; Roger, C.; et al. Effect of obesity on the population pharmacokinetics of fluconazole in critically ill patients. Antimicrob. Agents Chemother. 2016, 60, 6550-6557. [CrossRef] [PubMed]

47. Ghanem-Zoubi, N.; Qasum, M.; Khoury, J.; Zorbavel, D.; Arnon, M.; Geffen, Y.; Paul, M. The association between fluconazole dose and mic with mortality and persistence in candidemia. Eur. J. Clin. Microbiol. Infect. Dis. 2019, 38, 1773-1780. [CrossRef]

48. Pérez-Pitarch, A.; Ferriols-Lisart, R.; Aguilar, G.; Ezquer-Garín, C.; Belda, F.J.; Guglieri-López, B. Dosing of caspofungin based on a pharmacokinetic/pharmacodynamic index for the treatment of invasive fungal infections in critically ill patients on continuous venovenous haemodiafiltration. Int. J. Antimicrob. Agents 2018, 51, 115-121. [CrossRef]

49. Martial, L.C.; Ter Heine, R.; Schouten, J.A.; Hunfeld, N.G.; van Leeuwen, H.J.; Verweij, P.E.; de Lange, D.W.; Pickkers, P.; Brüggemann, R.J. Population pharmacokinetic model and pharmacokinetic target attainment of micafungin in intensive care unit patients. Clin. Pharmacokinet. 2017, 56, 1197-1206. [CrossRef]

50. Jullien, V.; Azoulay, E.; Schwebel, C.; Le Saux, T.; Charles, P.E.; Cornet, M.; Souweine, B.; Klouche, K.; Jaber, S.; Trouillet, J.L.; et al. Population pharmacokinetics of micafungin in icu patients with sepsis and mechanical ventilation. J. Antimicrob. Chemother. 2017, 72, 181-189. [CrossRef]

51. Grau, S.; Luque, S.; Campillo, N.; Samsó, E.; Rodríguez, U.; García-Bernedo, C.A.; Salas, E.; Sharma, R.; Hope, W.W.; Roberts, J.A. Plasma and peritoneal fluid population pharmacokinetics of micafungin in post-surgical patients with severe peritonitis. J. Antimicrob. Chemother. 2015, 70, 2854-2861. [CrossRef]

52. Pérez Civantos, D.V.; Robles Marcos, M.; Azanza Perea, J.R.; Pazos Pacheco, C.; García-Montoto Pérez, F.; Jerez Gómez-Coronado, V. Pharmacokinetics of anidulafungin in critically ill patients with candida peritonitis. Int. J. Infect. Dis. 2019, 86, 142-146. [CrossRef]

53. García-de-Lorenzo, A.; Luque, S.; Grau, S.; Agrifoglio, A.; Cachafeiro, L.; Herrero, E.; Asensio, M.J.; Sánchez, S.M.; Roberts, J.A. Comparative population plasma and tissue pharmacokinetics of micafungin in critically ill patients with severe burn injuries and patients with complicated intra-abdominal infection. Antimicrob. Agents Chemother. 2016, 60, 5914-5921. [CrossRef] 
54. Sinnollareddy, M.G.; Roberts, M.S.; Lipman, J.; Lassig-Smith, M.; Starr, T.; Robertson, T.; Peake, S.L.; Roberts, J.A. In vivo microdialysis to determine subcutaneous interstitial fluid penetration and pharmacokinetics of fluconazole in intensive care unit patients with sepsis. Antimicrob. Agents Chemother. 2015, 60, 827-832. [CrossRef] [PubMed]

55. Bergner, R.; Hoffmann, M.; Riedel, K.-D.; Mikus, G.; Henrich, D.M.; Haefeli, W.E.; Uppenkamp, M.; Walter-Sack, I. Fluconazole dosing in continuous veno-venous haemofiltration (cvvhf): Need for a high daily dose of $800 \mathrm{mg}$. Nephrol. Dial. Transpl. Off. Publ. Eur. Dial. Transpl. Assoc. Eur. Ren. Assoc. 2006, 21, 1019-1023. [CrossRef] [PubMed]

(C) 2020 by the authors. Licensee MDPI, Basel, Switzerland. This article is an open access article distributed under the terms and conditions of the Creative Commons Attribution (CC BY) license (http://creativecommons.org/licenses/by/4.0/). 